International Journal of Automotive and Mechanical Engineering (IJAME) ISSN: 2229-8649 (Print); ISSN: 2180-1606 (Online);

Volume 13, Issue 2 pp. 3401 - 3412, September 2016

CUniversiti Malaysia Pahang Publishing

DOI: https://doi.org/10.15282/ijame.13.2.2016.9.0281

\title{
Friction stir welding of similar and dissimilar aluminium alloys for automotive applications
}

\author{
N.F.M. Selamat ${ }^{1}$, A.H. Baghdadi ${ }^{1}$, Z. Sajuri ${ }^{1,2^{*}}$ and A.H. Kokabi ${ }^{3}$ \\ ${ }^{1}$ Department of Mechanical and Materials Engineering, Faculty of Engineering and \\ Built Environment, Universiti Kebangsaan Malaysia, \\ 43600 UKM Bangi, Selangor, Malaysia \\ ${ }^{2}$ Centre for Automotive Research, Faculty of Engineering and Built Environment, \\ Universiti Kebangsaan Malaysia, \\ 43600 UKM Bangi, Selangor, Malaysia \\ ${ }^{3}$ Department of Materials Science and Engineering, \\ Sharif University of Technology, Tehran, Iran \\ *Email: zsajuri@ukm.edu.my
}

\begin{abstract}
Aluminium alloys are lightweight materials relatively used in automotive industries. However, welding using the conventional welding methods is known to be difficult. In this study, the friction stir welding (FSW) known as the solid state joining process was extensively used for joining similar and dissimilar $5 \mathrm{~mm}$ aluminium alloy plates. The butt-joint type of similar joints (AA5083-AA5083) and dissimilar joints (AA5083AA6061) were carried out under the same welding parameters; $1000 \mathrm{rpm}$ (rotational speed) and $100 \mathrm{~mm} / \mathrm{min}$ (transverse speed). Macro- and microstructural observations were acquired at the cross-section of the weld regions by stereo and optical microscopes. The microstructural study showed that the formation of 'onion ring' structure was detected in the nugget zone of similar joints, while wavy and distorted patterns appeared in dissimilar joints. All tensile specimens of similar welding joint showed similar fracture patterns where all fractures occurred in the thermo-mechanically affected zone (TMAZ). However, tensile specimens of dissimilar welding joint broke up at the TMAZ region as well as at Al6061 base metal at the retreating side. The tensile strength of similar joint and dissimilar joint was 22\% and 19\% lower compared to the base metal of Al5083 and Al6061.
\end{abstract}

Keywords: Friction stir welding, dissimilar joint, thermo-mechanically affected zone, microstructure, aluminium alloy.

\section{INTRODUCTION}

In the automotive industry, aluminium alloys are demanding materials for various components due to its low density and good mechanical properties, especially when it is offered to weight reduction with high mechanical strength in the automotive industry [1, 2]. AA6061 contains Al-Mg-Si as an alloying element, whereas, AA5083 contains Al$\mathrm{Mg}$. Both of the aluminium alloys have been recognized as having high strength, good ductility and outstanding ability of corrosion resistant [3,4]. Since the beginning of aluminium alloys application in the automotive industry, studies on finding a reliable and suitable joining process are continuously pursued [5]. Aluminium alloys are known to be difficult to be joined using the conventional welding techniques until the friction stir 
welding (FSW) technique was invented at 1991 by The Welding Institute (TWI). FSW is a solid-state joining process that can be utilised on aluminium alloys or other materials such as copper, steel and titanium [6-10]. This technique has advantages in terms of joining light-weight materials and dissimilar materials during the welding process. Essentially, the principle of FSW is that a rotating pin is inserted and moved between two metals as shown in Figure 1. The rotating pin creates an interaction between the pin and base materials that produces frictional heat and leads to softening of the materials below the melting temperature. The temperature of aluminium alloys is less than $500^{\circ} \mathrm{C}$ during the FSW process $[11,12]$. The metals located on the same side as the welding direction are called the advancing side and the opposite metal is known as the retreating side. The cross section of the welding joint will produce different zones, particularly known as the base metal (BM), Heat Affected Zone (HAZ), Thermal-Heat Affected Zone (TMAZ) and Nugget Zone (NZ). Each zone experiences dissimilar plastic deformations, leading to different shapes of microstructure. In order to produce a sound welding joint, welding parameters such as rotational speed, transverse speed, and position of the metals either on the advancing or retreating side should be considered during the FSW process [13-15]. Research by Dawood et al. [16] found that reduction in surface roughness reduces friction and narrows down the HAZ at the welding joint. Deepati et al. [17] suggested that for dissimilar FSW AA5083 and AA1100, AA5083 should be placed on the advancing side. Meanwhile, taper cylindrical tool gives better hardness and tensile properties compared to straight cylindrical tool.

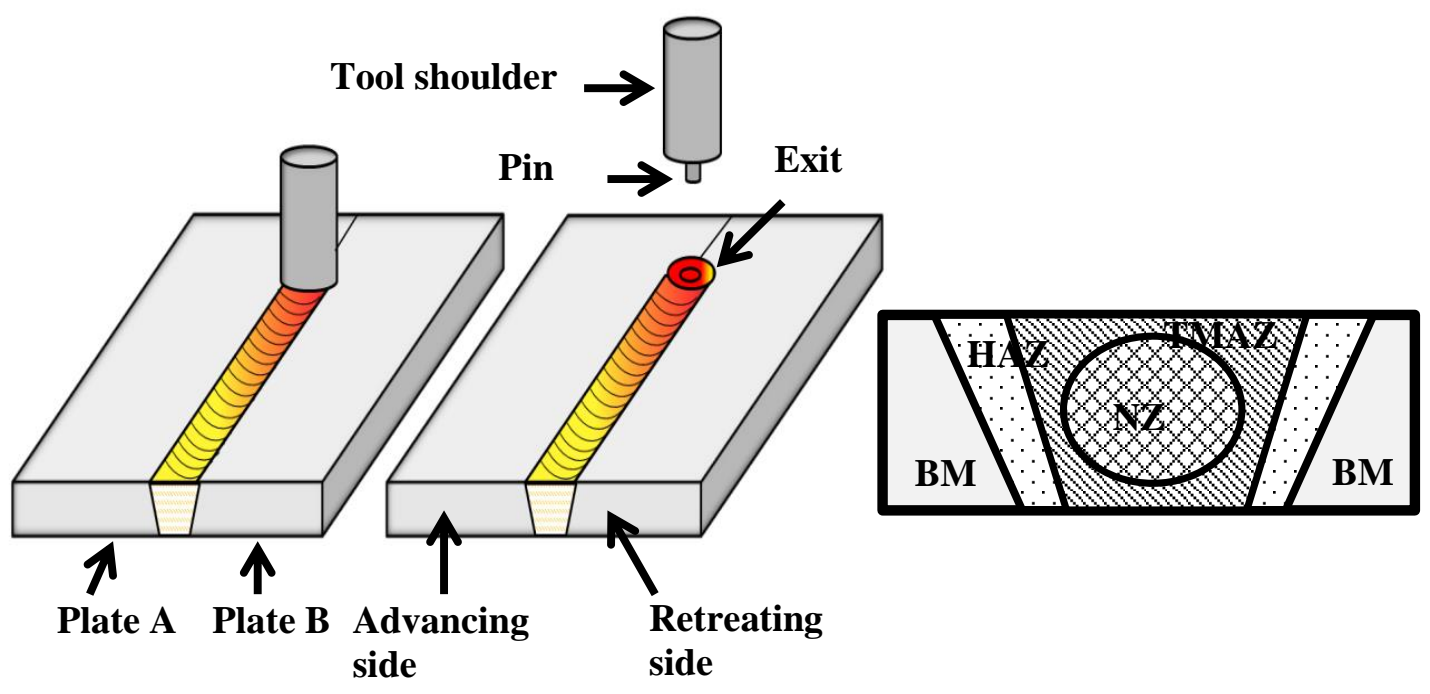

Note: Plate A and Plate B could be of the same or different materials

Figure 1. Schematic diagram of FSW process.

Furthermore, Hasan et al. proved that [18] threaded pin tool produces no defect at the welding joint compared to conical pin tool. Ilongavan et al. [19] showed that a rotation of $1100 \mathrm{rpm}$ and transverse speed of $22 \mathrm{~mm} / \mathrm{min}$ give higher welding efficiency by about $67.6 \%$ when using threaded cylindrical pin. The study by Ramachandran et al. [20] showed that most of the fractures of AA5052 and HSLA dissimilar joint occurred at the joint interface except for at $45 \mathrm{~mm} / \mathrm{min}$ and $500 \mathrm{rpm}$. Meanwhile, to improve mechanical strength, Sathari et al. [21] suggested that AA6061 should be located on the advancing side of the joint. Serio et al. [22] mentioned that a high rotational speed of 700 rpm could lead to cavity due to insufficient heat input supply during FSW. Successful 
studies on AA6061 and AA7075 by Ravikumar et al. [23] showed that improved joining can be achieved by reducing heat input, whereas the materials can be mixed well using low welding speed and high rotational speed. All previous works showed that FSW has a good potential for joining aluminium alloys. However, suitable welding parameters and types of material need to be considered in order to produce sound welding, especially for dissimilar alloys. Thus, in this research work, FSW is performed on similar joints AA5083-AA5083 and dissimilar joints AA5083-AA6061 in butt joints configuration. The objectives are to identify the weld-ability of similar and dissimilar aluminium alloys using the FSW technique and to evaluate the mechanical properties of similar and dissimilar joints of aluminium alloys.

\section{MATERIALS AND METHODS}

\section{Materials}

In this study, two types of aluminium alloys, AA5083 and AA6061, and $5 \mathrm{~mm}$ thickness rolled plates were used as the base metal for the FSW process. AA5083 is known as nonheat-treatable and AA6061 is heat-treatable aluminium alloys. The chemical composition and as-annealed mechanical properties of the aluminium alloys used in this study are listed in Table 1 and Table 2.

Table 1: Chemical compositions base metals (in wt.\%).

\begin{tabular}{llllllllll}
\hline Material & $\mathrm{Si}$ & $\mathrm{Fe}$ & $\mathrm{Cu}$ & $\mathrm{Mn}$ & $\mathrm{Mg}$ & $\mathrm{Cr}$ & $\mathrm{Zn}$ & $\mathrm{Ti}$ & $\mathrm{Al}$ \\
\hline AA5083 & 0.25 & 0.45 & - & 1.00 & 4.46 & 0.14 & 0.03 & 0.05 & Bal. \\
AA6061 & 0.52 & 0.70 & 0.39 & 0.15 & 0.88 & 0.24 & 0.16 & 0.14 & Bal. \\
\hline
\end{tabular}

Table 2: Mechanical properties of base metal (as-annealed).

\begin{tabular}{lcccc}
\hline Material & $\sigma_{y}(\mathrm{MPa})$ & $\sigma_{\text {UTS }}(\mathrm{MPa})$ & Elongation $(\%)$ & Hardness $(\mathrm{HV})$ \\
\hline AA5083 & 191 & 328 & 22 & 90 \\
AA6061 & 68 & 116 & 29 & 46 \\
\hline
\end{tabular}

\section{Experimental procedure}

The dimension of the welding plates was $150 \mathrm{~mm} \times 100 \mathrm{~mm} \times 5 \mathrm{~mm}$. They were clamped on the FSW machine as shown in Figure 2. The plates were butt-welded using the FSW machine parallel to the rolling direction. Prior to FSW, AA5083 was annealed at $345^{\circ} \mathrm{C}$ for 1.5 hours. Meanwhile, AA6061 was annealed at $415^{\circ} \mathrm{C}$ at two hours soaking time followed by cooling to $260^{\circ} \mathrm{C}$ at the rate of $20^{\circ} \mathrm{C}$ per hour, before the specimen was cooled to room temperature. The welding parameters were rotational speed, $\omega$, that was 1000 $\mathrm{rpm}$ and the pin travels, $v$, that was $100 \mathrm{~mm} / \mathrm{min}$. The pin geometry was simple and threaded as the dimension presented in Figure 2. The welding tool was made of H13 steel and was set inclined to the travel angle of $3^{\circ}$ for all experiments. Metallographic observation of the samples was done by grounding the samples mechanically, and lastly, the samples were polished with $0.1 \mu \mathrm{m}$ diamond suspension. Chemical etching was used to reveal the microstructure. To evaluate the tensile properties, tensile specimens with a gauge length of $40 \mathrm{~mm}$ and a width of $6 \mathrm{~mm}$ were machined perpendicular to the FSW direction. The tensile test was performed at a displacement rate of $2.4 \mathrm{~mm} / \mathrm{min}$ using a Zwick universal testing machine with $100 \mathrm{kN}$ load capacity. The tensile tests were performed on three specimens of the same welding joints. To identify the effect of FSW 
on the mechanical properties of the thermo-mechanically affected zone (TMAZ), Vickers hardness test was performed along the welding cross-section perpendicular to the welding direction using the Zwick Vickers micro hardness tester with an indentation load of $100 \mathrm{~g}$ in 15 seconds.

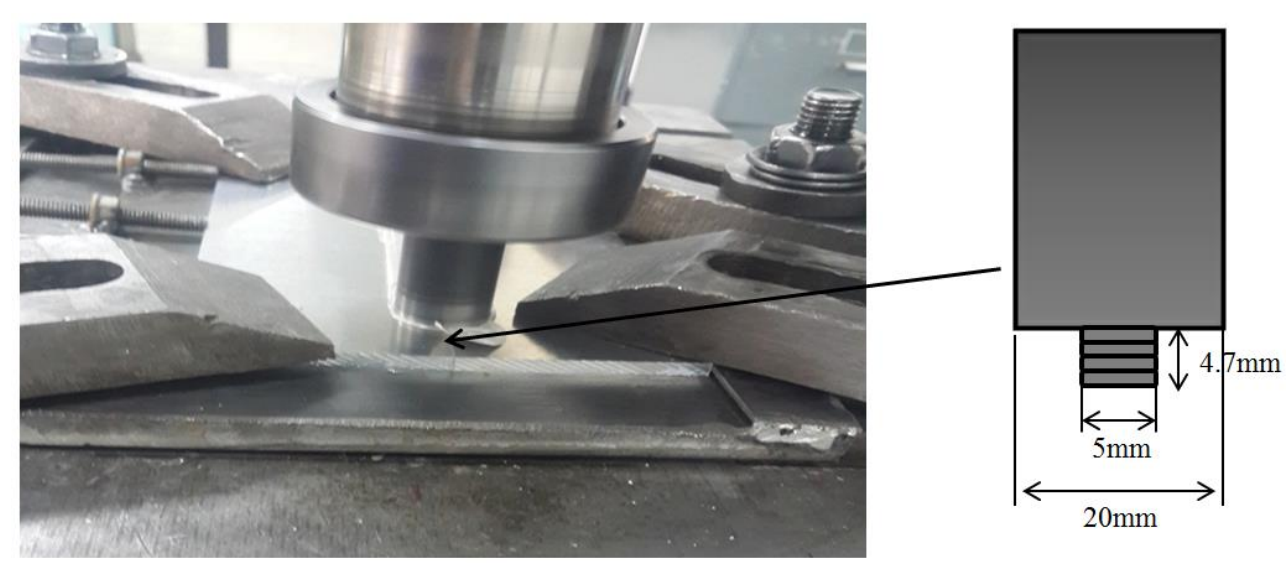

Figure 2. FSW machine and tool dimension.

\section{RESULTS AND DISCUSSION}

Figure 3 shows the top view of similar and dissimilar FSW of AA5083 and AA6061. Figure 3(a) displays the similar welding joints of AA5083-AA5083 and Figure 3(b) shows the dissimilar welding joints of AA5083-AA6061, with AA5083 as the advancing side in order to get better welding joint as mentioned by Dilip et al. [24]. A hole at the end of the weld indicated that the tool pin stopped after FSW. The width size of the weld was almost similar to the diameter of the pin shoulder, which was $20 \mathrm{~mm}$. A visual inspection showed that the weld surface of dissimilar joints of AA5083-AA6061 was smoother compared to that of similar joints AA5083-AA5083.

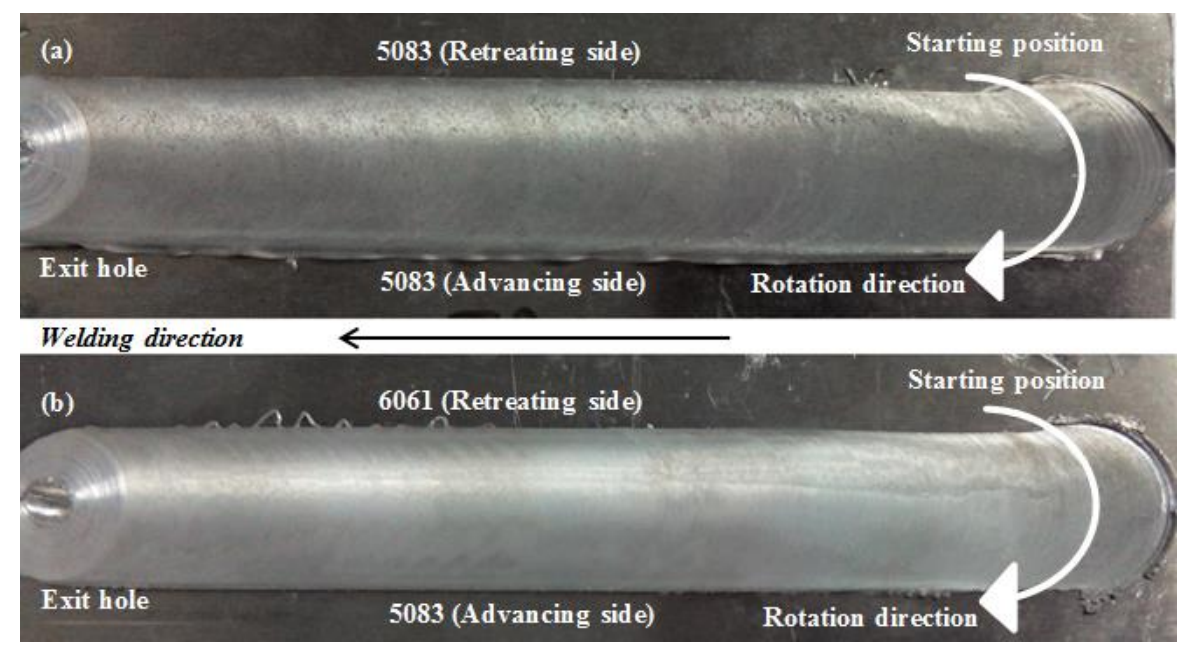

Figure 3. Top view of the FSW welds; (a) AA5083-AA5083 (b) AA5083-AA6061.

The smoother surface obtained is believed due to sufficient heat input supplied during the FSW process as also mentioned by RajKumar et al. and Yoon et al. in their 
studies $[25,26]$. The surface of the welding joint AA5083- AA5083 was slightly rough, with materials sticking on the pin tool during the joining process [21]. Moreover, the top surface of the welding joints were both defect-free with equally spaced ripples. The smooth and rough surfaces of the welding joints are believed to be related to the heat input during the FSW process. Furthermore, high frictional heat input will soften the materials, consequently producing a smooth welding surface.
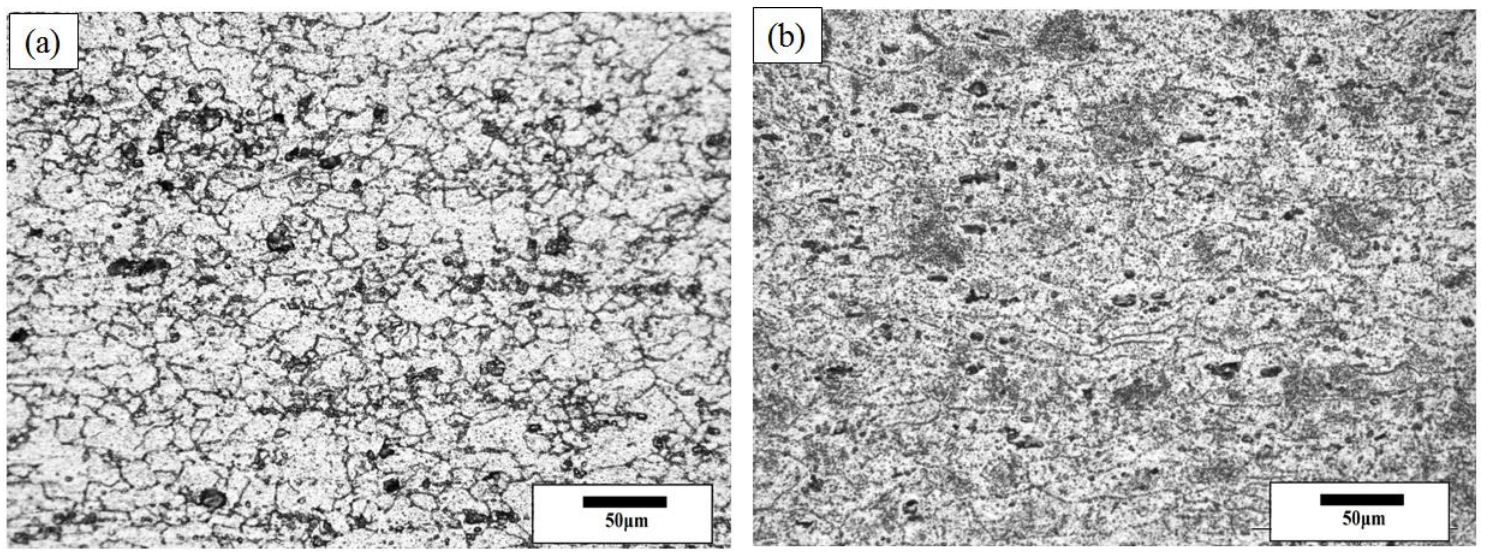

Figure 4. Microstructure of the base metal (a) AA5083 (b) AA6061.

The microstructures of AA5083 and AA6061 base metal were displayed in Figure 4. Microstructural observations on the cross-section of similar and dissimilar joints weld are shown in Figure 5 and Figure 6, respectively. Based on Figure 5, the macrostructures of AA5083-AA5083 displayed no defect in the welding region. The microstructures revealed that the nugget zone (NZ), heat affected zone (HAZ), and thermo-mechanical heat affected zone (TMAZ) appeared on the cross section of the welded joints. The FSW of AA5083-AA5083 in Figure 5 clearly exposed the onion ring pattern in NZ as indicated in regions ' $a$ ' and ' $b$ ' due to materials flowing during the FSW process. The onion ring pattern produced in the nugget zone was influenced by the movement of the pin tool in the material. Else, the effect of pin rotation had moved the materials at AS with lamella structure to fill up the unfilled space of the pin tool as found by Yoon et al. [27]. The fine grain size in the nugget zone indicated that some recrystallization occurred during the FSW process. Different patterns and grain sizes of the nugget zone in the welding region depend on the conditions and parameters used during the FSW process [28], especially the rotational speed of the welding tool [29].

Regions ' $c$ ' and ' $\mathrm{f}$ ' showed that the materials were heavily deformed in the TMAZ region towards the NZ region from the retreating side. Deformation of TMAZ structure is owing to high stress and large deformation occurring due to the mechanical force of the rotating pin, but not up to the recrystallization structure [30]. Regions ' $d$ ' and ' $e$ ' revealed that the materials from the advancing side deformed and bent toward NZ. TMAZ at the advancing side is significantly noticeable as abrupt microstructure as shown in Figure 5(e), which was due to tool movement and travel direction. This microstructural change in TMAZ has been commented by Uematsu et al.[31]. However, TMAZ at the retreating side was more diffuse and led to unclear TMAZ line [32].

Figure 6 shows welded regions in the dissimilar welding joints of AA5083AA6061. The macro-structure on the cross section of the dissimilar joint had contrasting colours due to different reactions to chemical reagent after being etched. It shows that AA5083 looked darker compared to AA6061. The macro-structures proved that no defect 
was formed during the FSW process. It shows that the materials on the advancing side was deposited on top of the welding regions. This is because the aluminium alloy 6xxx series are easily moved by tool and have good weld ability during FSW. Regions ' $a$ ' and ' $\mathrm{f}$ ' showed wavy and distorted patterns as obtained in the nugget zone.

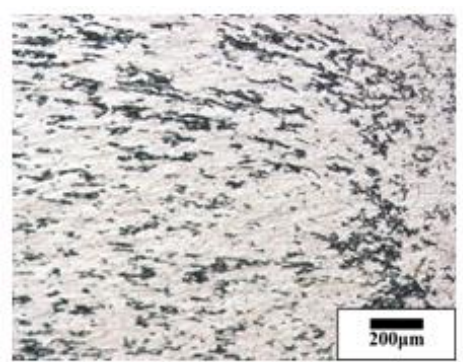

a) Region d

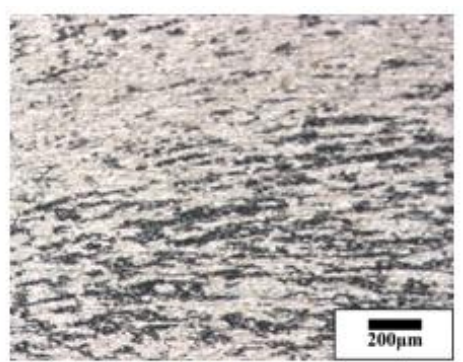

b) Region c

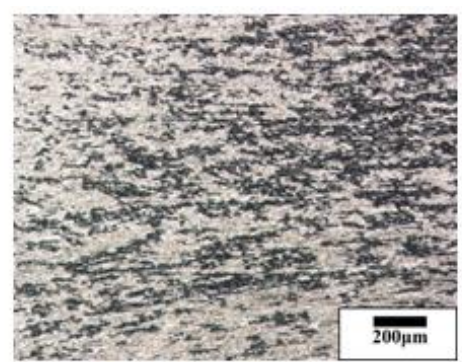

c) Region $f$

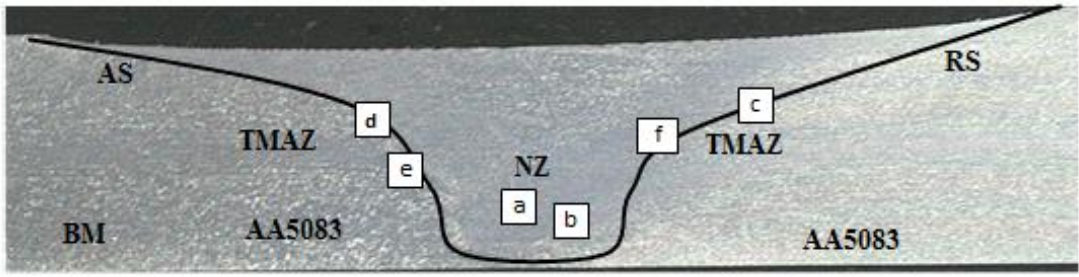

Macrostructure

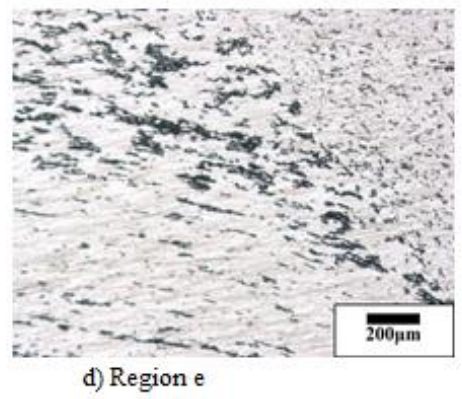

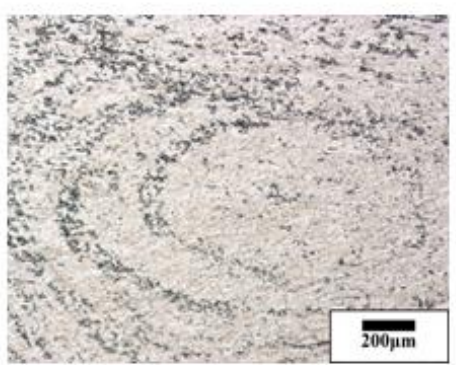

e) Region a

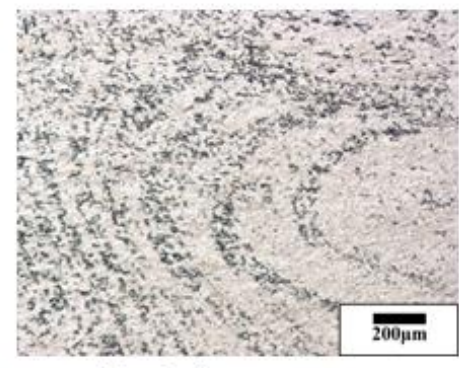

f) Region b

Figure 5. Microstructure of similar joints (AA5083- AA5083).

The pattern in the nugget is clarified the mixing behaviour between two materials, namely the distribution of materials was related to the mechanical effect of the welding process. Amancio et al. mentioned that the mixing pattern depends on the different flows, but not chemical mixing [33]. The pattern formed in NZ was due to the motion of plasticized materials under the rotating shoulder. AA6061 is more sensitive to flow and softening at high temperature, and easily forms plastic deformation, while AA5083 is more steady in softening at high temperature [34]. The microstructure of dissimilar welded joints can be categorized into few regions, which are unmixed regions, mechanically mixed and mixed flow which can be observed in regions 'c', ' $d$ ' and 'e' in Figure 6 as agreed by other researchers[35]. In the FSW process, temperature and strain rate deformation will vary the microstructure and cause changes in the hardness profile along the welding. The microhardness profile of both joints is illustrated in Figure 7. Similar joint of AA5083-AA5083 shows that hardness gradually decreased from the base metal towards the welding region under the pin shoulder, but still revealed asymmetric 'W' pattern from AS to RS. The hardness of base metal AA5083 was $90 \mathrm{Hv}$, compared to the average hardness under the pin shoulder that was approximately $84 \mathrm{Hv}$. It is indicated 
that the hardness in the welding zone was slightly lower at $6 \mathrm{Hv}$ compared to the base metal. The lowest hardness was located in the middle joint at approximately $76 \mathrm{Hv}$. The decreased hardness in NZ revealed that non-heat treatable AA5083 was softened due to heat input induced during FSW. The hardness was minimally reduced at TMAZ-NZ on the retreating side, whereas low hardness on the retreating side could lead to the fracture occurred in Figure 8during tensile test.

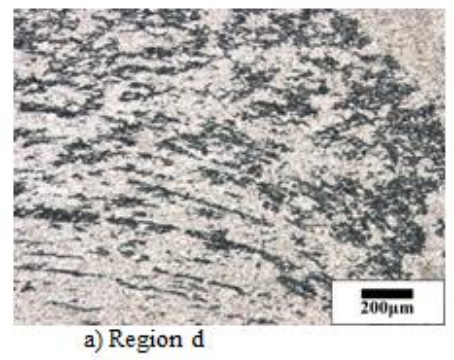

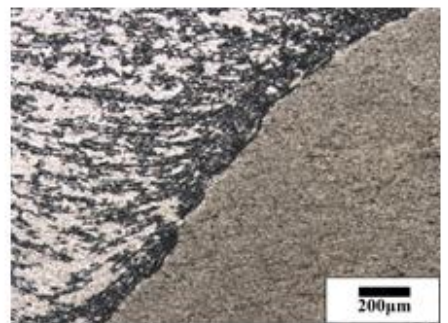

b) Region c

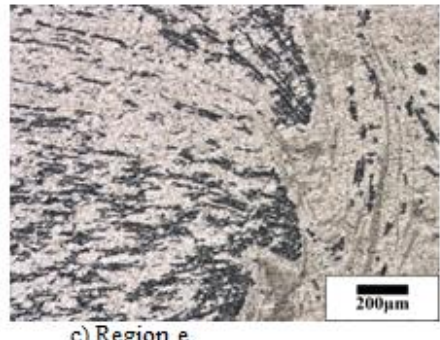

c) Region e

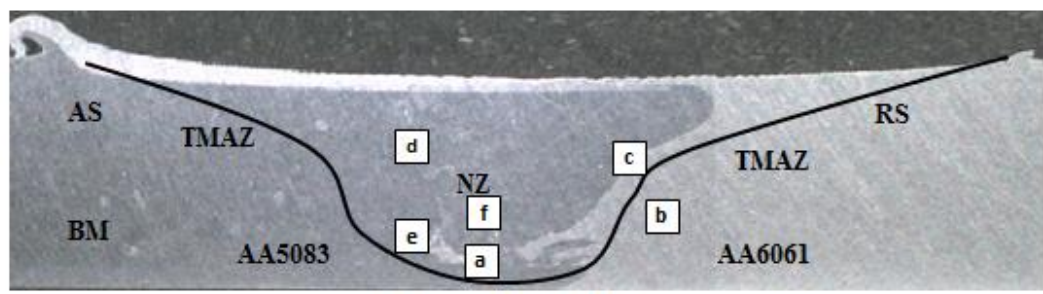

Macrostructure

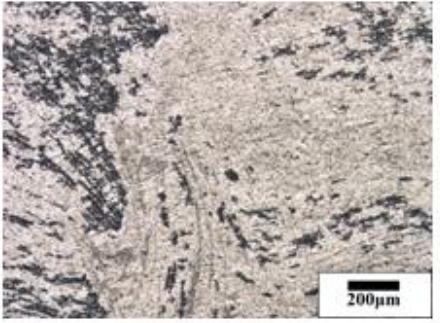

d) Region a

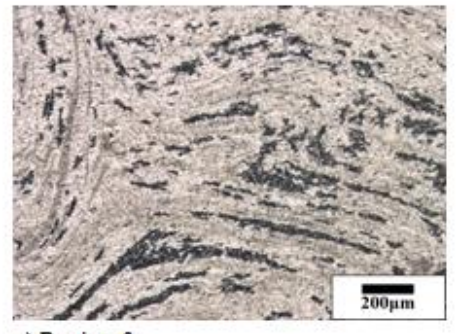

e) Region $f$

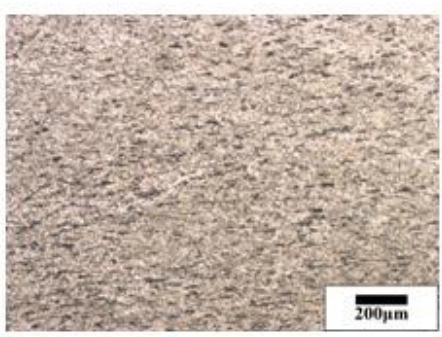

f) Region b

Figure 6. Microstructure of dissimilar joint (AA5083-AA6061).

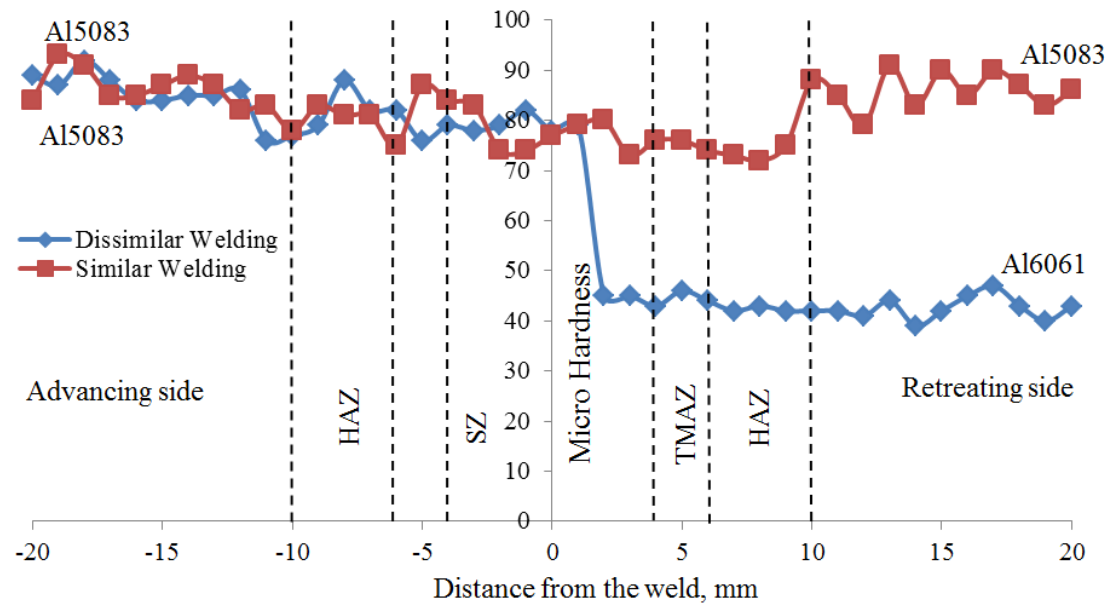

Figure 7. Hardness of cross section in weld joints. 
The hardness in NZ could be increased by reducing the rotational speed and increasing the transverse speed. Similar results were obtained by Rao et al. and Gungor et al. for similar [36] and dissimilar FSW joints [37]. In comparison, dissimilar joints of AA5083-AA6061 showed that hardness value gradually decreased from the advancing side (AA5083), starting from underneath the pin shoulder to the centre of the stir zone. However, upon entering the retreating side, the hardness significantly decreased from $80 \mathrm{HV}$ to $45 \mathrm{HV}$. Hardness reduction by about $35 \mathrm{HV}$ in the nugget zone was related to the low mechanical properties of AA6061 as indicated in region 'c' in Figure 6, which obviously showed the separated area between AA5083 and AA6061 during the intermixing process. The average hardness at the centre of the welding was $66 \mathrm{HV}$, which was slightly lower than the average hardness of both base metals $(68 \mathrm{Hv})$.

Figure 8 depicts the stress-strain diagram of base metal and welded joint. The result observed that the ultimate tensile strength of base metal AA5083 was the highest. The ultimate tensile strength of AA5083-AA5083 was 255Mpa, 23\% lower than AA5083 base metal. Sharma et al. found that similar joint of AA6061-AA6061 shows 66\% welding efficiency from the base metal AA6061 [38]. The strength of joints can be improved according to the sensitivity of the base metal, tool rotation as well as transverse speed as mentioned by Uematsu et al. [31]. Elongation reduced in the welded joint by as much as $36 \%$ from AA5083. The low elongation obtained in the welded joint is commonly observed in cold-work or precipitates harden aluminium since the strength was lost during the FSW process. For dissimilar joint AA6061-AA5083 the strength was $113 \mathrm{MPa}$ compared to $116 \mathrm{Mpa}$ of AA6061, leading to $97 \%$ of welding efficiency. Dissimilar joint was compared to AA6061 base metal because the fracture of the dissimilar joint was located at the retreating side (AA6061). Whereas, the elongation of dissimilar joint was 55\%, which was lower than AA6061, but was still high than similar joint. The high welding efficiency produced based on the chosen welding parameters can be considered as a suitable parameter to produce good weld-ability of aluminium alloys in industries.

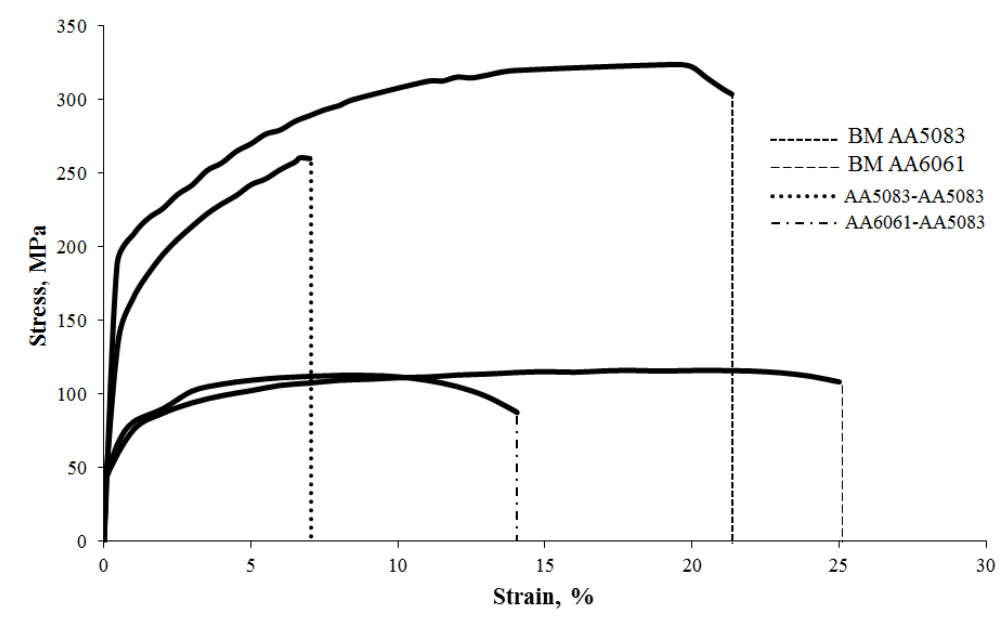

Figure 8. Transverse tensile properties of FSW joints.

In Figure 9, the tensile fracture results showed that similar joints were fractured at NZ-TMAZ located on the retreating side, where relatively occurred on low hardness TMAZ-NZ (retreating side) as displayed in Figure 7. Tensile specimens of dissimilar welding joint broke up at the retreating side of TMAZ and base metal AA6061. In order to comprehend the nature of fractures, the samples were examined using SEM. The morphologies of the fracture surface are shown in Figure 9. The different responses of 
microstructures and mechanical properties dependes on the type of base materials, particularly whether it will form dissimilar interact and dimples distribution during tensile test. Normally, when the superplastic deformation reaches the maximum limit, it will create nucleation of cavities. The cavities will coalesce to form dimple that grow into void consequence to the fractures. The dispersion of fine cavities on the fracture surface is favourable to grain boundary sliding (GBS), hence the stress concentration by GBS can be reduced by the existence of cavities [39]. AA6061-AA5083 shows a fracture surface that is covered with dimples and voids with varying depths and sizes. This behaviour is related to ductile behaviour and the formation of necking before fracture. The shallow dimples is obtained surrounding the transgular fracture surface. This is could be the reason for limited elongation during the tensile test and no necking occurring at the sample as indentified for joint AA5083-AA5083. Large void size that form after some deformation of dimples into $\mathrm{v}$-shape could be possible to reduce the strength and deteroite superplastic deformation of materials as stated by $\mathrm{Wu}$.
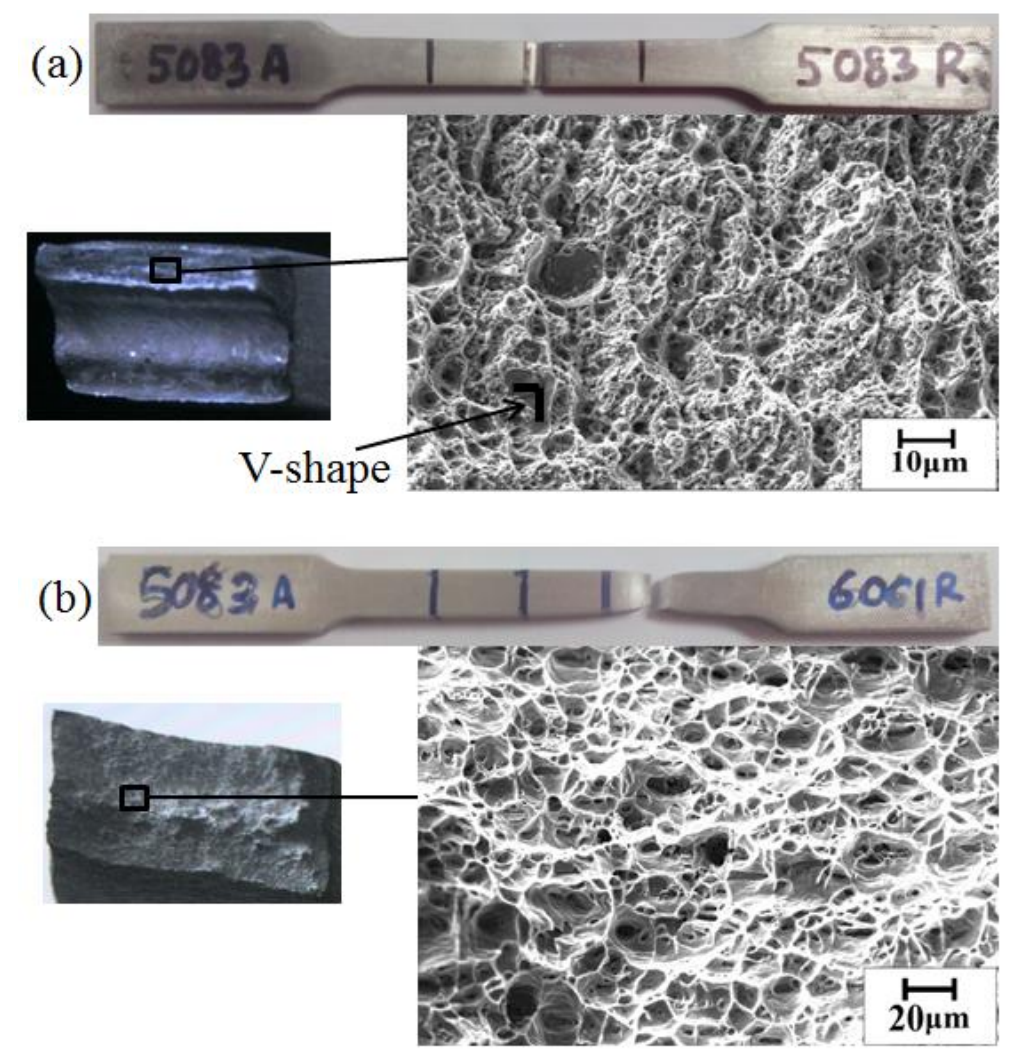

Figure 9. Macrograph and SEM images of the fracture surface,

\section{CONCLUSIONS}

FSW of similar (AA5083-AA5083) and dissimilar welding (AA5083-AA6061) was successfully performed using specific transverse speed $(100 \mathrm{~mm} / \mathrm{min})$ and rotational speed (1000 rpm) by simple and threaded pin tool.

i) Smooth surface welding on the joints depended on sufficient heat input applied during the FSW process, which was related to the transverse and rotational speed.

ii) Pin rotation during the stirring process resulted in the formation of onion ring and wavy distortion in the nugget zone for similar and dissimilar friction welding. The 
microstructure of the advancing side was more abrupt compared to the retreating side due to the movement of pin and materials on the advancing side.

iii) Micro-hardness indentation exhibited different hardness profiles, in which low hardness was obtained at the welding centre. Similar joint plots hardness at the base metal as $90 \mathrm{HV}$ and reduced to $76 \mathrm{HV}$ at the welding centre. Meanwhile, AA6061AA5083 showed reduced micro-hardness at the welded centre from $80 \mathrm{HV}$ to $35 \mathrm{HV}$ due to the mechanical properties of AA6061 on the retreating side.

iv) The welding efficiency of AA5083-AA5083 was 77\% from AA5083 base metal, whereas the efficiency of joint AA6061-AA5083 was 93\% and 34\% compared to AA6061 and AA5083, respectively. For future studies, it is suggested to use different types of pin for the same welding parameters to compare the weld-ability of joints.

\section{ACKNOWLEDGEMENTS}

The authors would like to express their gratitude to the Ministry of Higher Education, Malaysia (MOHE) through the Universiti Kebangsaan Malaysia for financial grants FRGS/1/2013/TK01/UKM/02/4. We are also indebted to Sharif University Technology, Tehran, Iran for assistance in FSW.

\section{REFERENCES}

[1] Chung K, Lee W, Kim D, Kim J, Chung K-H, Kim C, et al. Macro-performance evaluation of friction stir welded automotive tailor-welded blank sheets: Part IMaterial properties. International Journal of Solids and Structures. 2010;47:104862.

[2] Kim D, Lee W, Kim J, Chung K-H, Kim C, Okamoto K, et al. Macro-performance evaluation of friction stir welded automotive tailor-welded blank sheets: Part IIFormability. International Journal of Solids and Structures. 2010;47:1063-81.

[3] Wessel JK. The handbook of advanced materials: enabling new designs: John Wiley \& Sons; 2004.

[4] Shah LH, Akhtar Z, Ishak M. Investigation of aluminum-stainless steel dissimilar weld quality using different filler metals. International Journal of Automotive and Mechanical Engineering. 2013;8:1121-31.

[5] Thomas W, Nicholas E. Friction stir welding for the transportation industries. Materials \& Design. 1997;18:269-73.

[6] Kahl S, Osikowicz W. Composite aluminum-copper sheet material by friction stir welding and cold rolling. Journal of materials engineering and performance. 2013;22:2176-84.

[7] Chen Y, Liu C, Liu G. Study on the joining of titanium and aluminum dissimilar alloys by friction stir welding. Open Materials Science Journal. 2011;5:256-61.

[8] Aghajani H, Elyasi M, Hoseinzadeh M. Feasibility study on aluminum alloys and A441 AISI steel joints by friction stir welding. International Journal of Advanced Design and Manufacturing Technology. 2014;7.

[9] Shah LH, Mohamad UK, Yaakob KI, Razali AR, Ishak M. Lap joint dissimilar welding of aluminium AA6061 and galvanized iron using TIG welding. Journal of Mechanical Engineering and Sciences. 2016;10:1817-26.

[10] Sathari NAA, Razali AR, Ishak M, Shah LH. Mechanical strength of dissimilar AA7075 and AA6061 aluminum alloys using friction stir welding. International Journal of Automotive and Mechanical Engineering. 2015;11:2713-21. 
[11] Threadgill P, Leonard A, Shercliff H, Withers P. Friction stir welding of aluminium alloys. International Materials Reviews. 2013.

[12] Sathari NAA, Shah LH, Razali AR. Investigation of Single-pass/double-pass techniques on friction stir welding of aluminium. Journal of Mechanical Engineering and Sciences. 2014;7:1053-61.

[13] Charitidis C, Dragatogiannis D, Koumoulos E, Kartsonakis I. Residual stress and deformation mechanism of friction stir welded aluminum alloys by nanoindentation. Materials Science and Engineering: A. 2012;540:226-34.

[14] Hasan MM, Ishak M, Rejab MRM. A simplified design of clamping system and fixtures for friction stir welding of aluminium alloys. Journal of Mechanical Engineering and Sciences. 2015;9:1628-39.

[15] Ahmad R, Asmael MBA. Effect of aging time on microstructure and mechanical properties of AA6061 friction stir welding joints. International Journal of Automotive and Mechanical Engineering. 2015;11:2364-72.

[16] Dawood HI, Mohammed KS, Rahmat A, Uday M. The influence of the surface roughness on the microstructures and mechanical properties of 6061 aluminium alloy using friction stir welding. Surface and Coatings Technology. 2015;270:272-83.

[17] Deepati AK, Tikaderb S, Chaturvedi H, Biswas P. Experimental Investigation of Mechanical Properties on Friction Stir Welding of Dissimilar Aluminum Alloys. 2014.

[18] Hasan A, Bennett C, Shipway P. A numerical comparison of the flow behaviour in Friction Stir Welding (FSW) using unworn and worn tool geometries. Materials \& Design. 2015;87:1037-46.

[19] Ilangovan M, Boopathy SR, Balasubramanian V. Microstructure and tensile properties of friction stir welded dissimilar AA6061-AA5086 aluminium alloy joints. Transactions of Nonferrous Metals Society of China. 2015;25:1080-90.

[20] Ramachandran K, Murugan N, Kumar SS. Influence of tool traverse speed on the characteristics of dissimilar friction stir welded aluminium alloy, AA5052 and HSLA steel joints. Archives of Civil and Mechanical Engineering. 2015;15:82230.

[21] Ishak M, Noordin NFM, Razali ASK, Shah LHA, Romlay FRM. Effect of filler on weld metal structure of AA6061 aluminum alloy by tungsten inert gas welding. International Journal of Automotive and Mechanical Engineering, 11, 24382446.

[22] Serio LM, Palumbo D, De Filippis LAC, Galietti U, Ludovico AD. Effect of friction stir process parameters on the mechanical and thermal behavior of 5754H111 aluminum plates. Materials. 2016;9:122.

[23] Ravikumar S, Rao VS, Pranesh R. Effect of Process parameters on mechanical properties of friction stir welded dissimilar materials between AA6061-T651 and AA7075-T651 alloys. Journal of Engineering Science and Technology. 2015; 10(6): 790-801 .

[24] Dilip J, Koilraj M, Sundareswaran V, Ram GJ, Rao SK. Microstructural characterization of dissimilar friction stir welds between AA2219 and AA5083. Transactions of The Indian Institute of Metals. 2010;63:757-64.

[25] RajKumar V, VenkateshKannan M, Sadeesh P, Arivazhagan N, Ramkumar KD. Studies on effect of tool design and welding parameters on the friction stir welding of dissimilar aluminium alloys AA 5052-AA 6061. Procedia Engineering. 2014;75:93-7. 
[26] Sung-Ook Y, Myoung-Soo K, Hyun-Bin N, Yong-Jai K, Sung-Tae H, Jin-Chun $\mathrm{K}$, et al. Friction stir butt welding of A5052-O aluminum alloy plates. Transactions of Nonferrous Metals Society of China. 2012;22:s619-s23.

[27] Yoon T-J, Yun J-G, Kang C-Y. Formation mechanism of typical onion ring structures and void defects in friction stir lap welded dissimilar aluminum alloys. Materials \& Design. 2016;90:568-78.

[28] Hirata T, Oguri T, Hagino H, Tanaka T, Chung SW, Takigawa Y, et al. Influence of friction stir welding parameters on grain size and formability in 5083 aluminum alloy. Materials Science and Engineering: A. 2007;456:344-9.

[29] Steuwer A, Peel M, Withers P. Dissimilar friction stir welds in AA5083-AA6082: the effect of process parameters on residual stress. Materials Science and Engineering: A. 2006;441:187-96.

[30] Rajamanickam N, Balusamy V. Effects of process parameters on mechanical properties of friction stir welds using design of experiments. Indian Journal of Engineering and Materials Sciences. 2008;15:293-9.

[31] Uematsu Y, Tokaji K, Shibata H, Tozaki Y, Ohmune T. Fatigue behaviour of friction stir welds without neither welding flash nor flaw in several aluminium alloys. International Journal of Fatigue. 2009;31:1443-53.

[32] Leitao C, Louro R, Rodrigues D. Using torque sensitivity analysis in accessing Friction Stir Welding/Processing conditions. Journal of Materials Processing Technology. 2012;212:2051-7.

[33] Amancio-Filho S, Sheikhi S, Dos Santos J, Bolfarini C. Preliminary study on the microstructure and mechanical properties of dissimilar friction stir welds in aircraft aluminium alloys 2024-T351 and 6056-T4. Journal of materials processing technology. 2008;206:132-42.

[34] Park S-K, Hong S-T, Park J-H, Park K-Y, Kwon Y-J, Son H-J. Effect of material locations on properties of friction stir welding joints of dissimilar aluminium alloys. Science and Technology of Welding and Joining. 2010;15:331-6.

[35] Palanivel R, Mathews PK, Dinaharan I, Murugan N. Mechanical and metallurgical properties of dissimilar friction stir welded AA5083-H111 and AA6351-T6 aluminum alloys. Transactions of Nonferrous Metals Society of China. 2014;24:58-65.

[36] Rao D, Huber K, Heerens J, Dos Santos J, Huber N. Asymmetric mechanical properties and tensile behaviour prediction of aluminium alloy 5083 friction stir welding joints. Materials Science and Engineering: A. 2013;565:44-50.

[37] Gungor B, Kaluc E, Taban E, Sik A. Mechanical, fatigue and microstructural properties of friction stir welded 5083-H111 and 6082-T651 aluminum alloys. Materials \& Design. 2014;56:84-90.

[38] Sharma C, Dwivedi DK, Kumar P. Effect of welding parameters on microstructure and mechanical properties of friction stir welded joints of AA7039 aluminum alloy. Materials \& Design. 2012;36:379-90.

[39] Sun P-h, Wu H-y, Lee W-s, Shis S-h, Perng J-y, Lee S. Cavitation behavior in superplastic $5083 \mathrm{Al}$ alloy during multiaxial gas blow forming with lubrication. International Journal of Machine Tools and Manufacture. 2009;49:13-9. 